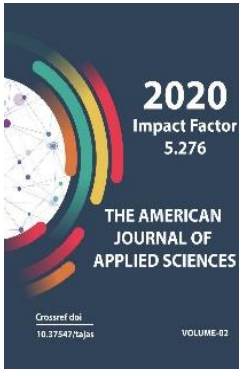

Journal Website: http://usajournalshub.c om/index,php/tajas

Copyright: Original content from this work may be used under the terms of the creative commons attributes 4.0 licence.

\section{Features Of The Reaction Of The Cardiorespiratory System Of Children To Dynamic And Isometric Load In The Republic Of Karakalpakstan}

\author{
N.P. Mirametova \\ PhD in Biological Sciences, Nukus State Pedagogical Institute, Nukus, Uzbekistan \\ G.N. Taumuratova \\ PhD in Biological Sciences, Nukus State Pedagogical Institute, Nukus, Uzbekistan
}

\title{
ABSTRACT
}

The article is devoted to the study of the mechanisms of adaptation of the organism of children to various types of activity. The analysis showed that the girls had a significant increase in stroke and minute blood volume, as well as an increase in systolic, diastolic and pulse blood pressure. In boys, these changes were less pronounced.

\section{KEYWORDS}

Karakalpakstan, cardiorespiratory system, physical activity, mechanoreceptors, blood pressure.

\section{INTRODUCTION}

One of the most important tasks of modern physiology is to study the mechanisms of adaptation of the body to various types of activity. (Vanyushin et al., 2002, Drattsev, 2008). The cardiorespiratory system, which provides oxygen to the cells of the body, is one of the most important physiological systems, which defines how mental and the physical performance of children in ontogenesis and during adaptation to educational activity (Krysiuk, 2007, Ferguson et.al., 2007). The required levels of the minute volume of respiration can be provided only if there is an appropriate functional reserve and maturity of the mechanisms for regulating respiration, which ensures economizing of the functioning of the respiratory system.

It is known that the ecological conditions of the Southern Aral Sea region have significantly deteriorated in recent years. According to a number of researchers (Abdirov et al., 1995; Eshanov, 2003; Mambetullaeva, 2010), the 
health status of the population continues to deteriorate significantly in a number of indicators. The greatest changes have taken place in the indicators of the health status of children, who, due to the imperfection of the body's defenses, are the first among other groups of the population to react to the unfavorable environmental situation in the region. Their body is a kind of marker of increased sensitivity to the state of the environment.

\section{LITERATURE REVIEW}

It is known that the age of 7-10 years old children is on the border of two important periods in the development of the respiratory system. This age period is also characterized by smooth changes in morphological and functional indicators. At the same time, there is an increase in reserve and functional indicators. This age is considered the pinnacle of the effectiveness of the "child" organization of physiological functions, as well as a variety of options for the individual organization of energy metabolism.

The somatic, functional and psychophysiological maturity of children requires the attention of specialists in various fields, serious interdisciplinary research, unified methodological approach.

The peculiarity of physiological changes occurring in the respiratory system under static stresses, the quickly onset of fatigue, make them an important object for study, especially in the process of adaptation of younger schoolchildren. The study of the dynamics of indicators of external respiration and the cardiovascular system of primary schoolchildren for various types of loads during the school year seems to be very relevant at the present time.

During the growth and development of the child, afforestation from the motor apparatus and other analyzers plays an increasing role in the regulation of breathing. Thanks to their development and a more subtle analysis of the information entering the brain, the respiratory center receives more and more objective data on the beginning and amount of physical activity (Burykh et al., 2007).

Experts have found that with age, breathing becomes more and more corticalized and controlled (Breslav, 1985; Sonkin, 2007). Also, with age, there is a tendency towards a decrease in the relative value of the minute volume of respiration, a deepening and decrease in the frequency of respiration. With physical exertion of moderate and high power, a decrease in volumetric breathing rates occurs, indicating fatigue of the respiratory muscles (Coats et al., 2003). In children, immaturity of the mechanoreceptor and central mechanisms of respiration regulation is observed (Sokolov et al., 2000). This, in turn, may determine the inadequacy of physiological changes in the respiratory system in the process of adaptation of primary schoolchildren to the training load.

Various types of stress cause a sharp increase in oxygen consumption in the nervous and muscular systems of the child. Therefore, it becomes necessary to ensure the increased consumption of oxygen by organs and tissues. This function is provided by breathing - the exchange of gases between the external environment and the cells of the human body. Convection transport of respiratory gases combines two processes - pulmonary ventilation and transport of gases by the circulatory system. Thus, the cardiorespiratory system is a single whole, providing the necessary level of redox processes in cells.

The cardiorespiratory system, which provides oxygen to the cells of the body, is one of the most important physiological systems, which defines how mental and the physical performance of children in ontogenesis and during adaptation to educational activities (Krysiuk 2007, Ferguson et al., 2007).

The required levels of the minute volume of respiration can be provided only if there is an 
appropriate functional reserve and maturity of the mechanisms for regulating respiration, which ensures economizing of the functioning of the respiratory system (Sokolov et al., 2000; Rossiter et al., 2003). External or pulmonary respiration, which carries out gas exchange between the external environment and the blood of the pulmonary capillaries, in the process of age-related development, it undergoes significant changes in connection with the growth and formation of the Broncho pulmonary apparatus (Shiryaeva, 1978).

Despite numerous studies on the problems of studying the adaptation systems of modern children, however, a number of issues were not discussed, or were not considered comprehensively, in a narrow range of ontogenesis. In recent years, most of the works of modern researchers have been devoted to the physical development of children (Makhmudov et al., 2001; Maturazova, 2008), and the results of complex functional studies (Abramovskikh, 2007).

At present, the ecological conditions of the Southern Aral Sea region (including the Republic of Karakalpakstan) have significantly deteriorated in recent years. According to a number of experts (Abdirov et al., 1993; Mambetullaeva, 2012), the health status of the population continues to deteriorate significantly in a number of indicators. The greatest changes have taken place in the indicators of the health status of children, who, due to the imperfection of the body's defenses, are the first among other groups of the population to react to the unfavorable environmental situation in the region.

In total, 140 children born and living in various regions of Karakalpakstan were examined. Dosed physical activity was set on a bicycle ergometer with magnetic braking and was 1.0 watts per $1 \mathrm{~kg}$ of the child's body weight, the duration of work was 5 minutes, the frequency was $60 \mathrm{rpm}$.
In the course of the study, we found that primary schoolchildren have two important periods in the development of the external respiration system: in 6-7 years, when there is a significant decrease in bronchial resistance, which leads to an increase in the volume of inspiration and expiration, and 10-11 years - a period of intensive increase in lung volume. The general patterns of the development of the functions of external respiration, its reserve and adaptive capabilities in the ontogenesis of children have been comprehensively studied by specialists (Vorontsov, 1986).

\section{THE MAIN FINDINGS AND RESULTS}

The analysis of the obtained data shows that at the beginning of the school year, after the cycle ergo metric load, all the studied parameters of the external respiration system changed insignificantly in children of elementary grades studying in educational institutions of the Republic of Karakalpakstan at the beginning of the school year. After the dynamic load, the boys of the first grade at the beginning of the school year showed an increase in the maximum breathing volume due to an increase in the respiratory rate.

In the course of the study, it was also found that isometric load at the beginning of the school year led to a decrease in the values of most indicators of external respiration in boys in the first year of school. There was a decrease in the value of the respiratory minute volume (RMV) to $8.57+0.61 \mathrm{l} / \mathrm{min}(\mathrm{p}$ $<0.01)$ due to a decrease in the respiratory rate (RR).

The results obtained indicate a significant negative effect of isometric load in girls, which indicates a higher degree of adaptive capabilities of the girls' external respiration system to physical activity and to unfavorable environmental living conditions. It was also found that the isometric load did not lead to significant changes in the parameters of external respiration in boys and girls in the 
middle of the school year. In studies carried out at the end of the school year, isometric load in girls led to an increase in RMV ( $p$ $<0.05)$ due to increased respiration. Here, the inspiratory reserve volume (IRV) also increased. The values of other indicators of external respiration (tidal volume, maximum ventilation of the lungs, etc.) in children of both sexes did not change.

When performing standard physical activities, children have greater relative pulmonary ventilation compared to adults (Kolchinskaya, 1964). One of the possible explanations for this fact may be the differences in the morphology of the external respiration apparatus of children and adults. For ventilation, children need more effort to overcome airway resistance. For a general idea of the work of external respiration, information can be cited that the total work of the respiratory muscles at rest in children 8 years old is $0.38 \mathrm{kgm} / \mathrm{min}$, and the component of elastic work is $72,2 \%$.

\section{CONCLUSION}

A decrease in the indicators of the elastic work of the respiratory muscles at different ages is mainly associated with an increase in the elasticity of the lung tissue, which in 8 year old schoolchildren is $46.7 \mathrm{ml} / \mathrm{cm}$ of water. Art., and in children 13-14 years old $-120.8 \mathrm{ml} /$ $\mathrm{cm}$ of water. Art. (Ketkin et al.., 1984).

In the course of the study, it was found that isometric exercise had a different effect on the cardiovascular system of girls and boys. The girls showed a significant increase in stroke and minute blood volume, as well as an increase in systolic, diastolic and pulse blood pressure. In boys, these changes were less pronounced. These differences, in our opinion, can be explained by the peculiarities of the reaction of heart rate variability indicators in girls and boys to isometric exercise. In boys, their dynamics clearly indicated the predominance of the parasympathetic regulation channel.
Thus, it can be noted that children born in unfavorable environmental conditions of the Republic of Karakalpakstan, revealed some excess of the level of indicators in the functioning of the adaptive respiratory system.

\section{REFERENCES}

1. Abdirov Ch.A., Agadzhanyan N.A., Severin A.E. Ecology and human health. - Nukus, 1993. - $184 \mathrm{p}$.

2. Abramovskikh N.A. Physical development of children in conditions of deterioration of the main indicators of the socio-economic situation of the population of the Kurgan region. Tyumen, 2007.

3. Vorontsov I.M. Regularities of physical development of children and methods of its assessment // Educationalmethodical. Manual. - L., 1986.- 56 p.

4. Gubareva L.I., Ermolenko G.V. Physical development of adolescents and microelementosis // Stavropol, 2005.p. 38-40.

5. Eshchanov T.B. Medico-ecological zoning of the Republic of Karakalpakstan in the light of the state of health of the mother and child // Environmental factors and health of mothers and children in the region of the Aral crisis: Materials of the international. seminar. - Tashkent: SUB, 2001. - 11-14 p.

6. Zayneev M.M., Sitdikov F.G., Ziyatdinova N.I., Zefirov T.L. The reaction of the cardiorespiratory system of first-graders to various types of load during the school year/l Kazan Medical Journal. - 2008. - T.89.№ 6.- p. 8330-834.

7. Ketkin A.T., Varlamova N.G., Evdokimov V.G. Anthropometric indicators and physical performance. Human physiology.- Moscow:, 1984.T.10.- № 1.- p. 112-116. 
8. Klimova T.V. The relationship of various exogenous environmental factors and the health status of older preschool children // Fundamental research. -2005 . - № 5 - p. 17-20

9. Konstantinova L.G., Kurbanov A. B., Atanazarov K. M. Drinking water quality, health status of the population and prognosis of morbidity in the Republic of Karakalpakstan // Environmental factors and health of mothers and children in the Aral Sea crisis region: Proceedings of the Intern. seminar. -Nukus: Sub, 2001. -p. 87-95.

10. Lazarev V.F. The state of the environment and the health of children in rural areas of the Penza region: Author's abstract. diss. Cand. med. Sciences. - Moscow:, 2001.- p.23.

11. Makhmudov O.S., Shamsiev F.M., Karimov U.A., Khudaibergenov M.A., Mambetkarimov G.A. Morbidity in children of the first year of life in an ecologically unfavorable region of the Aral Sea region // Vestn. KCO AN RUz. 2001. - №5. -p. 8-10.

12. Maturazova E.M. Characteristics of indicators of the blood and circulatory system in children in the conditions of the Southern Aral Sea region - author. Cand. diss. - Tashkent:, 2008.- 16 p. 